\title{
Mapeamento sistemático de teses e dissertações sobre os egressos do ensino médio integrado de 2014 a 2019
}

\section{Systematic mapping of theses and dissertations about graduates from integrated high school 2014-2019}

Recebido: 05/01/2020 | Revisado: 05/04/2020 | Aceito: 15/06/2020 |

Publicado: 19/04/2021

Camila lorrane Costa Santana

ORCID: https://orcid.org/0000-0002-81153097

Instituto Federal de Educação, Ciência e Tecnologia do Maranhão

E-mail: camilasantana@acad.ifma.edu.br

Odaléia Alves da Costa

ORCID: https://orcid.org/0000-0002-83992054

Instituto Federal de Educação, Ciência e

Tecnologia do Maranhão

E-mail: odaleia@ifma.edu.br

Como citar:

SANTANA, C. I. C.; COSTA, O. A.;

XXXXX, X. X.; Mapeamento sistemático de teses e dissertaç̃es sobre os egressos do ensino médio integrado de 2014 a 2019. Revista Brasileira da Educação Profissional e Tecnológica, [S.I.], v. 1, n. 20, p. e10021, abr. 2021. ISSN 2447-1801.

This work is licensed under a Creative Commons Attribution 4.0 Unported License.

\section{Resumo}

Este artigo objetiva analisar Teses e Dissertações que abordem a temática do egresso da Educação Profissional Técnica de Nível Médio (EPTNM), na modalidade integrada. Como procedimento metodológico foi realizada uma busca avançada na Biblioteca Digital Brasileira de Teses e Dissertações (BDTD), utilizando os descritores: "Egressos" e "Educação Profissional e Tecnológica"/ "Egressos" e "Ensino Médio Integrado"/ "Egressos" e "Curso Técnico", após a busca foram aplicados critérios de exclusão estabelecidos nesta pesquisa, resultando em 25 produções científicas a serem analisadas. Os resultados revelaram que dentre as Teses e Dissertações 8 (32\%) são advindas de programas de pós-graduação em Educação. Foi possível evidenciar também que $80 \%$ dos egressos investigados nos trabalhos são oriundos de Institutos Federais (IFs). Além disso, constatou-se que os comentadores brasileiros são utilizados com maior frequência (86 vezes) do que teóricos estrangeiros (24 vezes), quando analisadas as referências. $E$ que o instrumento de coleta de dados mais utilizado em produções que envolvem esta temática foi o questionário empregado em 15 produções (60\%).

Palavras-chave: Egresso. Educação Profissional e Tecnológica. Ensino Médio Integrado. Mapeamento Sistemático.

\section{Abstract}

This article aims to analyze Theses and Dissertations that address the issue of graduates from Vocational Technical Education of Middle Level (EPTNM), in the integrated modality. As a methodological procedure, an advanced search was carried out at the Biblioteca Digital Brasileira de Teses e Dissertações (BDTD), using the descriptors: "Graduates" and "Professional and Technological Education" / "Graduates" and "Integrated High School" / "Graduates" and "Technical Course", after the search, exclusion criteria established in this research were applied, resulting in 25 scientific productions to be analyzed. The results reveal that among the Theses and Dissertations $8(32 \%)$ are from postgraduate in education. It was also evident that $80 \%$ of the graduates investigated in the researches comes from Federal Institutes (IF's). In addition, it was found that Brazilian commentators are used more often (86 times) than foreign theorists (24 times), when the references are analyzed. And the data collection instrument most used in productions involving this theme is the questionnaire used in 15 productions $(60 \%)$.

Keywords: Graduates. Professional and Technological Education. Integrated High School. Systematic Mapping.Curriculum. Pedagogical Practice. Human development. 


\section{INTRODUÇÃO}

Este estudo trata-se de uma revisão sistemática de literatura. Esse tipo de estudo teve origem nas Ciências Biomédicas e não são costumeiramente desenvolvidos nas Ciências Sociais e Humanas. Contudo a relevância deste tipo de revisão, se apresenta no fato desta "organizar, analisar criticamente e levantar evidências mais sólidas, ou seja, integrar o número cada vez maior de peças do complexo quebra-cabeça da produção científica" (COSTA; ZOLTOWSKI, 2014, p. 69).

Assim sendo, Cordeiro et al., (2007, p. 429), afirma que para a produção de uma revisão sistemática de qualidade é necessária a elaboração de uma problemática adequada, pois é através desta, que se "define quais serão as estratégias adotadas para identificar os estudos que serão incluídos e quais serão os dados que necessitam ser coletados de cada estudo".

Considerando este pressuposto a problemática desta pesquisa é a seguinte: na temática dos egressos da Educação Profissional Técnica de Nível Médio (EPTNM), onde se encontram localizados geograficamente os lócus das pesquisas dentro deste tema? Em quais universidades estes trabalhos foram produzidos? Que autores foram mais utilizados como fundamentação teórica? E quais as metodologias abordadas pelos pesquisadores que estudam este assunto?

O egresso é considerado como indivíduo que não pertence mais a instituição e se encontra na esfera de diplomado, egresso este da EPTNM. Segundo a Lei no 9.394, de 20 de dezembro de 1996 a qual apresenta as Diretrizes e Bases da Educação Nacional (LDB), em seu artigo 36-A, estabelece que através da EPTNM "o ensino médio, atendida a formação geral do educando, poderá prepará-lo para o exercício de profissões técnicas", podendo ser oferecida pelo Sistema Federal de Ensino e por Sistemas estaduais, distrital e municipais e se desenvolver, segundo artigo 36-B e 36-C, de duas formas, primeiramente articulada ao Ensino Médio e na segunda forma, subsequente, como pode ser visto na Figura 1.

Figura 1: Representação das articulações da EPTNM de acordo com a Lei oํ 9. $394 / 1996$

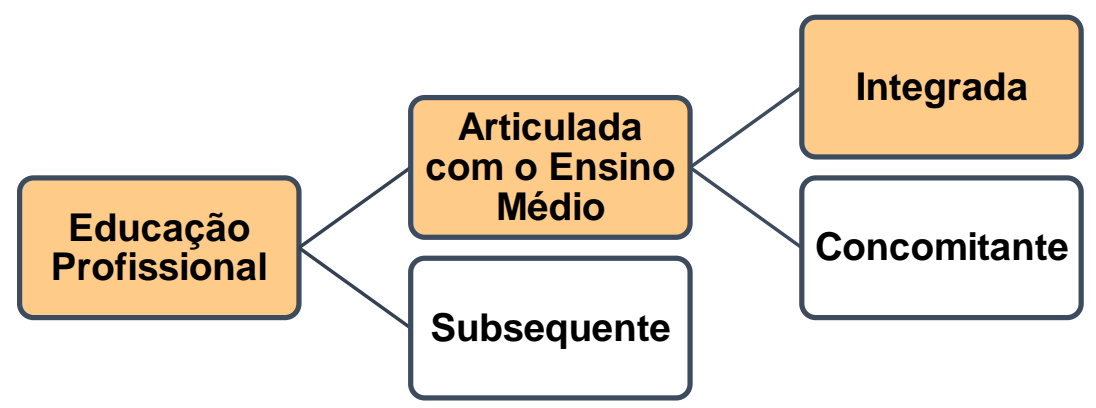

Fonte: Elaborada pelas pesquisadoras a partir da Lei nº 9394/1996

A forma articulada ao Ensino Médio, apresenta-se na modalidade integrada, que é "oferecida somente a quem já tenha concluído o ensino fundamental, sendo o 
curso planejado de modo a conduzir o aluno à habilitação profissional técnica de nível médio, na mesma instituição de ensino, efetuando-se matrícula única para cada aluno". E na modalidade concomitante "oferecida a quem ingresse no ensino médio ou já o esteja cursando, efetuando-se matrículas distintas para cada curso". A segunda forma de ser desenvolvida é através da forma subsequente, a qual se destina aos alunos que já concluíram o Ensino Médio. Neste artigo o objetivo foi analisar Teses e Dissertações que abordam a temática dos egressos pertencentes a modalidade integrada da EPTNM, que está em destaque na Figura 1.

\section{METODOLOGIA}

Com o objetivo de subsidiar a produção de uma dissertação de mestrado, servindo como ponto de partida na concretização da produção do conhecimento científico, a utilização da elaboração de um artigo de mapeamento sistemático, se apresenta devido a sua caracterização, definidas segundo Lopes e Fracolli (2008, p. 772) como sendo: "fontes de busca abrangentes, seleção dos estudos primários sob critérios aplicados uniformemente e avaliação criteriosa da amostra".

Este trabalho se caracteriza como uma pesquisa qualitativa a qual segundo André e Gatti (2008, p. 4) este tipo de pesquisa tende a "responder ao desafio da compreensão dos aspectos formadores/formantes do humano, de suas relações e construções culturais, em suas dimensões grupais, comunitárias ou pessoais."

$\mathrm{Na}$ busca pela obtenção do objetivo proposto neste estudo a técnica de pesquisa utilizada foi de revisão bibliográfica que se constitui pelo estudo de produções já elaboradas como livros e publicações periódicas, esta possui como vantagem a possibilidade de ampliação na gama de informação acerca da problemática requerida pelo pesquisador. (GIL, 2002, p. 45).

Por se tratar de uma pesquisa de revisão sistemática a partir de produção científicas (bibliografias), foram consideradas etapas básicas de elaboração deste tipo de pesquisa. Apresentadas por Costa e Zoltowski (2014, p. 56), as etapas são as seguintes:

delimitação da questão a ser pesquisada, escolha das fontes de dados, eleição das palavras-chaves para a busca, busca e armazenamento dos resultados, seleção [...] de acordo com critérios de inclusão e exclusão, extração dos dados, avaliação e síntese e interpretação dos dados.

Desta forma, foi desenvolvida uma análise das produções científicas, encontradas na Biblioteca Digital Brasileira de Teses e Dissertações (BDTD) do Instituto Brasileiro de Informação em Ciência e Tecnologia (IBCIT), através de uma busca avançada. Neste tipo de busca é possível selecionar o ano de publicação dos trabalhos disponíveis na biblioteca, facilitando a busca pelos trabalhos publicados de 2014 a 2019, juntamente com a utilização dos seguintes descritores entre aspas: "Egressos" e "Educação Profissional e Tecnológica" / "Egressos" e "Ensino Médio Integrado" / "Egressos" e "Curso Técnico". 
No Quadro 1, pode-se observar a quantificação do total inicial das Teses e Dissertações, o total de produções que se encaixaram nos critérios estabelecidos e as que fizeram parte da pesquisa proposta.

Quadro 1: Quantidade de Teses e Dissertações disponíveis na BDTD/IBICT sobre os Egressos do EPTNM da modalidade integrada e total de produções analisadas

\begin{tabular}{|c|c|c|c|c|c|}
\hline \multirow[t]{2}{*}{ Descritores } & \multirow{2}{*}{$\begin{array}{l}\text { Total } \\
\text { Inicial }\end{array}$} & \multicolumn{3}{|c|}{ Excluídos } & \multirow{2}{*}{$\begin{array}{l}\text { Produções } \\
\text { científicas } \\
\text { analisadas }\end{array}$} \\
\hline & & C1 & $\mathrm{C2}$ & C3 & \\
\hline $\begin{array}{l}\text { "Egressos" } \\
\text { Profissional e Tecnológica" }\end{array}$ & 30 & 0 & 19 & 2 & 9 \\
\hline $\begin{array}{l}\text { "Egressos" e "Ensino Médio } \\
\text { Integrado" }\end{array}$ & 19 & 4 & 7 & 0 & 8 \\
\hline "Egressos" e "Curso Técnico" & 80 & 18 & 42 & 12 & 8 \\
\hline TOTAL & 129 & 22 & 68 & 14 & 25 \\
\hline
\end{tabular}

Fonte: Elaborado pelas pesquisadoras a partir dos dados analisados da BDTD (2020)

Após a busca dos descritores na BDTD foi realizada a leitura dos títulos e resumos dos trabalhos encontrados para a aplicação dos três critérios de exclusão estabelecidos. Inicialmente foi empregado o critério 1 (C1) - trabalhos em duplicidade dentre os descritores, totalizando 22 produções excluídas.

Em seguida ocorreu a aplicação do critério 2 (C2) - trabalhos que não tratassem sobre egressos da Educação Profissional Técnica de Nível Médio, ao qual se enquadrou 68 pesquisas distribuídas da seguinte forma: 52 produções não trabalhavam com a temática do egresso, 6 se referiam a egressos do Ensino Superior e 10 investigavam os egressos do Programa Nacional de Acesso ao Ensino Técnico e Emprego (PRONATEC).

Por fim foi utilizado o critério 3 (C3) - trabalhos que abordassem outra modalidade da EPTNM além da integrada, resultando em 14 produções excluídas, das quais 6 abordavam os egressos da modalidade subsequente, 3 investigavam 0 Programa Nacional de Integração da Educação Profissional com a Educação Básica na Modalidade de Educação de Jovens e Adultos (PROEJA) e 5 trabalhos apresentavam a análise de mais de uma das modalidades de EPTNM. Esta distribuição pode ser notada na Figura 2. 
Figura 2: Quantitativo de Teses e Dissertações desde a busca avançada realizada na BDTD, aplicação dos critérios de exclusão e total de trabalhos analisados

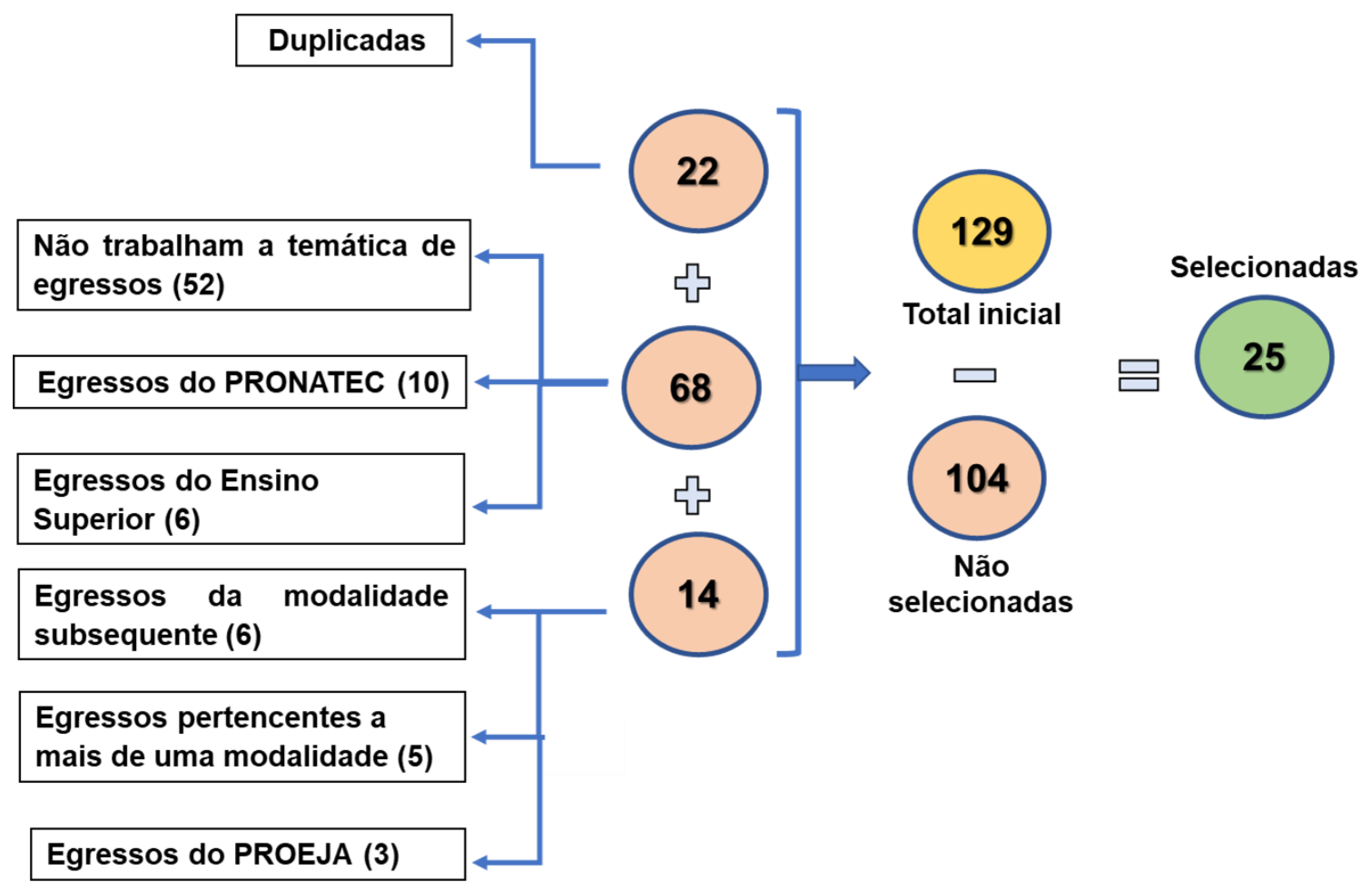

Fonte: Elaborada pelas pesquisadoras a partir dos dados analisados da BDTD (2020)

Foram analisados, portanto, 25 trabalhos entre teses e dissertações, disponíveis na Biblioteca Digital Brasileira de Teses e Dissertações (BDTD), conforme Quadro 2, organizado por ano de publicação do trabalho.

Quadro 2: Teses e Dissertações sobre a temática dos egressos da Educação Profissional Técnica de Nível Médio publicadas na BDTD entre 2014 e 2019

\begin{tabular}{|c|c|c|c|}
\hline $\mathbf{N}^{\circ}$ & Ano & Autor (a) & Título \\
\hline 1 & 2014 & $\begin{array}{l}\text { NASCIMENTO, Suzete } \\
\text { Viana }\end{array}$ & $\begin{array}{l}\text { Avaliação da política pública de educação } \\
\text { profissional: eficácia e efetividade dos } \\
\text { cursos técnicos no Instituto Federal Bahia. }\end{array}$ \\
\hline 2 & 2014 & PEREIRA, Christiane Cruz & $\begin{array}{l}\text { Implementação da Política de ensino } \\
\text { Médio Integrado no Ceará: relações de } \\
\text { influências entre os processos de gestão e } \\
\text { análise dos resultados de inserção } \\
\text { produtiva e ingresso acadêmico dos } \\
\text { egressos da política. }\end{array}$ \\
\hline 3 & 2014 & RAYKIL, Eladyr Boaventura & $\begin{array}{l}\text { Impacto dos cursos técnicos integrados e } \\
\text { subsequentes na vida profissional dos } \\
\text { egressos: reflexos do primeiro quinquênio } \\
\text { do IFBA - Campus Porto Seguro. }\end{array}$ \\
\hline 4 & 2014 & $\begin{array}{l}\text { SANTIAGO, Luciana Maria } \\
\text { Montenegro }\end{array}$ & $\begin{array}{l}\text { Curso técnico em enfermagem integrado } \\
\text { ao ensino médio: caracterização e } \\
\text { trajetória profissionais dos egressos por } \\
\text { meio da utilização das redes sociais. }\end{array}$ \\
\hline
\end{tabular}


Revista Brasileira da Educação Profissional e Tecnológica, v. 1, n. 20, e10021, 2021, p. 6 de 19 CC BY 4.0 | ISSN 2447-1801 | DOI: https://doi.org/10.15628/rbept.2021.10021

\begin{tabular}{|c|c|c|c|}
\hline 5 & 2014 & SOUZA, Flávia Antunes & $\begin{array}{l}\text { Avaliação da Política Pública de Educação } \\
\text { Profissional nos Institutos Federais: Uma } \\
\text { análise da experiência do Instituto Federal } \\
\text { de Educação, Ciência e Tecnologia do Rio } \\
\text { de Janeiro (IFRJ). }\end{array}$ \\
\hline 6 & 2015 & ARTIAGA, Débora Martins & $\begin{array}{l}\text { A articulação do ensino médio com a } \\
\text { educação profissional no IF Sudeste MG - } \\
\text { Campus Muriaé. }\end{array}$ \\
\hline 7 & 2015 & $\begin{array}{l}\text { CARNEIRO, Thaline Teixeira } \\
\text { Novaes }\end{array}$ & $\begin{array}{l}\text { O ensino médio profissional no IF } \\
\text { baiano/Senhor do Bonfim-BA: } \\
\text { desenvolvimento humano na percepção de } \\
\text { egressos. }\end{array}$ \\
\hline 8 & 2016 & $\begin{array}{l}\text { CANCIAN, Rosânia Araújo } \\
\text { Silva }\end{array}$ & $\begin{array}{l}\text { Perfil e empregabilidade dos egressos dos } \\
\text { campi Agropecuários de Colorado do } \\
\text { Oeste e Ariquemes do Instituto Federal de } \\
\text { Educação, Ciência e Tecnologia de } \\
\text { Rondônia. }\end{array}$ \\
\hline 9 & 2016 & $\begin{array}{l}\text { COUTINHO, Eduardo } \\
\text { Henrique Lacerda }\end{array}$ & $\begin{array}{l}\text { Políticas públicas para educação } \\
\text { profissional e tecnológica e o mundo do } \\
\text { trabalho contemporâneo: um estudo de } \\
\text { caso dos egressos dos Cursos Técnicos } \\
\text { Integrados do CEFET-MG. }\end{array}$ \\
\hline 10 & 2016 & $\begin{array}{l}\text { GRANGEIRO, Humberlandia } \\
\text { Moreira Bezerra }\end{array}$ & $\begin{array}{l}\text { Os cursos técnicos de nível médio e as } \\
\text { percepções de egressos de uma Escola } \\
\text { Estadual de Educação Profissional do } \\
\text { Ceará. }\end{array}$ \\
\hline 11 & 2016 & MARQUES, Daniele Luciano & $\begin{array}{l}\text { Entre a escola unitária e a mercadológica: } \\
\text { a trajetória para o mundo do trabalho dos } \\
\text { egressos das EEEPs do Ceará. }\end{array}$ \\
\hline 12 & 2016 & OLIVEIRA, Elias Vieira de & $\begin{array}{l}\text { Avaliação de impacto da formação técnica } \\
\text { para inserção dos alunos egressos do } \\
\text { campus Brasília no mundo do trabalho. }\end{array}$ \\
\hline 13 & 2016 & SILVA, Ademir Antônio da & $\begin{array}{l}\text { Egressos do Instituto Federal de } \\
\text { Educação, Ciência e Tecnologia de } \\
\text { Sergipe - IFS - Campus Lagarto: } \\
\text { formação e atuação no mundo do trabalho. }\end{array}$ \\
\hline 14 & 2016 & SOUSA, Paulo Cícero & $\begin{array}{l}\text { Ensino técnico e emprego: uma análise } \\
\text { dos egressos do curso técnico em } \\
\text { petroquímica do instituto federal do Ceará - } \\
\text { campus Caucaia. }\end{array}$ \\
\hline 15 & 2017 & CAÚ, José Nildo Alves & $\begin{array}{l}\text { A juventude do curso técnico integrado em } \\
\text { agropecuária ao IFPE: desejos, } \\
\text { expectativas e experiências vivenciadas } \\
\text { para construção do seu projeto de vida. }\end{array}$ \\
\hline 16 & 2017 & $\begin{array}{l}\text { CERQUEIRA, Yara Dias } \\
\text { Fernandes }\end{array}$ & $\begin{array}{l}\text { Institutos Federais e Desenvolvimento } \\
\text { Local: O IFSULDEMINAS - Campus } \\
\text { Machado - como expressão dos limites e } \\
\text { possibilidades da Educação Profissional e } \\
\text { Tecnológica na sociedade brasileira } \\
\text { contemporânea. }\end{array}$ \\
\hline 17 & 2017 & $\begin{array}{l}\text { SOUZA, Helaine Christina } \\
\text { Oliveira de }\end{array}$ & $\begin{array}{l}\text { Percursos da Educação Profissional } \\
\text { técnica de nível médio integrado no IFPR } \\
\text { de Telêmaco Borba/PR: uma análise } \\
\text { sociológica. }\end{array}$ \\
\hline 18 & 2018 & CARDOSO, Pierre Pinto & $\begin{array}{l}\text { Empregabilidade dos egressos: a } \\
\text { educação profissional integrada ao ensino } \\
\text { médio no extremo norte da Amazônia. }\end{array}$ \\
\hline 19 & 2018 & $\begin{array}{l}\text { CARVALHO JUNIOR, José } \\
\text { Roberto Abreu }\end{array}$ & $\begin{array}{l}\text { Uma proposta de intervenção gerencial } \\
\text { para a inserção dos egressos de cursos }\end{array}$ \\
\hline
\end{tabular}


Revista Brasileira da Educação Profissional e Tecnológica, v. 1, n. 20, e10021, 2021, p. 7 de 19 CC BY 4.0 | ISSN 2447-1801 | DOI: https://doi.org/10.15628/rbept.2021.10021

\begin{tabular}{|c|c|c|c|}
\hline & & & $\begin{array}{l}\text { técnicos do IFES campus Guarapari no } \\
\text { mercado de trabalho local. }\end{array}$ \\
\hline 20 & 2018 & DAVIDIS, Nancy da Luz & $\begin{array}{l}\text { Ensino técnico profissionalizante, mercado } \\
\text { de trabalho e renda: a experiência do } \\
\text { Campus Ceilândia do Instituto Federal de } \\
\text { Brasília. }\end{array}$ \\
\hline 21 & 2018 & FEITOSA, Jair Freitas & $\begin{array}{l}\text { Aspirações dos alunos do ensino médio } \\
\text { Integrado do Instituto Federal do Piauí - } \\
\text { campus Floriano: levantamento e análise. }\end{array}$ \\
\hline 22 & 2018 & $\begin{array}{l}\text { LEAL NETO, Alberto Álvaro } \\
\text { Vasconcelos }\end{array}$ & $\begin{array}{l}\text { Entre diálogos e reflexões: o que os } \\
\text { egressos do curso médio-técnico em } \\
\text { Geologia têm a nos dizer sobre formação } \\
\text { humana? }\end{array}$ \\
\hline 23 & 2018 & $\begin{array}{l}\text { SANTOS, Carla Augusta } \\
\text { Nogueira Lima }\end{array}$ & $\begin{array}{l}\text { Formação e atuação profissional: um } \\
\text { estudo comparativo com egressos do } \\
\text { curso técnico em lazer do IFMA e de curso } \\
\text { de graduação em lazer e turismo da } \\
\text { EACH/USP. }\end{array}$ \\
\hline 24 & 2019 & $\begin{array}{l}\text { MARTINS, Reginaldo } \\
\text { Marcos }\end{array}$ & $\begin{array}{l}\text { Aspectos de caráter crítico-social no curso } \\
\text { técnico em administração integrado ao } \\
\text { ensino médio: Um estudo de caso a partir } \\
\text { dos trabalhos de conclusão de curso dos } \\
\text { estudantes. }\end{array}$ \\
\hline 25 & 2019 & $\begin{array}{l}\text { ZIBENBERG, Igor Ghelman } \\
\text { Sordi }\end{array}$ & $\begin{array}{l}\text { Das disposições sociais aos habitus } \\
\text { estudantis: as incorporações do êxito } \\
\text { escolar no ensino médio integrado. }\end{array}$ \\
\hline
\end{tabular}

Fonte: Elaborado pelas pesquisadoras a partir dos dados analisados da BDTD (2020)

Seguindo este pressuposto adotou-se, a Análise de Conteúdo, na qual organiza-se em torno de três etapas sequenciais: a pré-análise, a exploração do material, o tratamento dos resultados, a inferência e a interpretação (BARDIN, 2006, p. 95).

Após a seleção dos trabalhos foi realizada quatro análises, a primeira de origem institucional desenvolvida através da busca dos lócus das pesquisas nas produções científicas. A segunda foi referente a fundamentação teórica, essa se deu a partir da busca nas referências pela menção de autores que foram utilizados nas discussões das Teses e Dissertações. Em seguida foi realizada a análise das metodologias empregadas, nesta busca objetivou-se conhecer quais instrumentos de coleta de dados foram mais utilizados pelos autores que desenvolveram trabalhos nesta temática.

Por fim, foi realizada uma análise de dados textuais, feita através da utilização do software Iramuteq, este se encontra disponível gratuitamente na internet. Para que essa etapa inicial de instalação se concretizasse foi necessário primeiramente instalar o software $\mathrm{R}$ que também se encontra gratuito, pois realiza o processamento estatístico dos dados na produção das análises efetuadas através do Iramuteq. Após sua devida instalação, a investigação se deu a partir da interpretação de corpus textuais, que consiste no agrupamento do texto que será analisado (CAMARGO; JUSTO, 2013). Neste artigo, os resumos das Teses e Dissertações foram os corpus textuais utilizados.

Portanto, foram produzidas duas investigações: a nuvem de palavras e a análise de similitude a partir dos corpus textuais, sendo possível respectivamente 
quantificar a frequência das palavras e destacar o grau de conectividade entre elas. Cabe mencionar que apenas os verbos, nomes comuns e adjetivos presentes nos resumos foram considerados na produção destas análises, todos com uma frequência de apresentação de no mínimo 10 vezes.

\section{RESULTADOS E DISCUSSÕES}

Constatou-se dentre as 25 produções selecionadas que, 22 são oriundas de universidades públicas, posto que 20 são de universidades federais e 2 de universidades estaduais. As demais produções são de instituições privadas, provenientes das seguintes universidades: Pontifícia Universidade Católica de São Paulo, Universidade Católica de Salvador e a Universidade Nove de Julho. Destacando além disso que foram produzidas através de 14 programas de pósgraduação diversos, destes se destacando programas em Educação (8 produções), Administração (4 produções) e Gestão Pública (3 produções).

Outro dado apresentado se refere ao ano de publicação das pesquisas, analisadas, 19 dissertações e 6 teses publicadas nos últimos seis anos, destacou-se com um número de produções mais elevado o ano de 2016, como pode ser observado no Quadro 3.

Quadro 3: Quantidade de produções disponíveis na BDTD/IBICT sobre os Egressos do EPTNM da modalidade integrada por ano

\begin{tabular}{|l|l|l|l|}
\hline ANO & Dissertações & Teses & Total \\
\hline 2014 & 05 & 00 & 05 \\
\hline 2015 & 02 & 00 & 02 \\
\hline 2016 & 06 & 01 & 07 \\
\hline 2017 & 02 & 01 & 03 \\
\hline 2018 & 03 & 03 & 06 \\
\hline 2019 & 01 & 01 & 02 \\
\hline
\end{tabular}

Fonte: Elaborado pelas pesquisadoras a partir dos dados analisados da BDTD (2020)

A EPTNM é ofertada nacionalmente e se expandiu de forma conjunta com as instituições que fornecem esta modalidade de ensino como os Institutos Federais de Educação, Ciência e Tecnologia. A Rede Federal de Educação Profissional, Científica e Tecnológica, formada a partir do conjunto de instituições de ensino que ofertam educação profissional, segundo Turmena e Azevedo (2017) passou por três fases de expansão entre os anos de 2008 a 2014. Considerando essa perspectiva e analisando pela ótica de que as produções científicas publicadas em 2016 foram produzidas, provavelmente, entre os anos de 2014 a 2016, observa-se que suas produções se apresentaram em uma fase da história da EPTNM em que a expansão ocorrida pode ter sido ponto de partida para questionamentos acerca de seus resultados, vislumbrando nos egressos desta modalidade suas respostas, desta forma destacando-se o ano de 2016 como sendo o ano com a maior quantidade de publicações desenvolvidas sobre esta temática. 
De acordo com um de estudo de avaliação do plano de expansão da Rede Federal de ensino, segundo indicadores de desempenho realizado por Silva et al., (2019), a partir do ano de 2016 ocorreu um aumento no número de alunos formados em relação ao total de matrículas realizadas. Este crescimento no número de egressos aconteceu após o período de expansão da Rede Federal, evidenciando assim de maneira conjunta o aumento no número de egressos, bem como o aumento de pesquisas envolvendo egressos.

Além das instituições pertencentes à Rede Federal, outras instituições também ofertam a EPTNM, como as que obtêm assistência através do Programa Brasil Profissionalizado que tem como base legal o Decreto 6.302 de 12 de dezembro de 2007, o qual objetiva incentivar a promoção da articulação do ensino médio e a educação profissional, através do financiamento das propostas apresentadas pelos estados, municípios e o Distrito Federal.

Dentre os trabalhos analisados, 20 destes apresentaram-se como produções científicas que abordam o egresso da EPTNM, tendo como lócus da pesquisa os Institutos Federais (IFs), 4 referentes a egressos oriundos de Escolas Estaduais de Educação Profissional (EEEPs) do estado do Ceará e 1 trabalho realizado na Escola Técnica Estadual de São Paulo. Na busca de compreender a origem institucional destes egressos em âmbito regional, foi analisado a quais IFs estes egressos pertencem.

No Gráfico 1, encontra-se a distribuição da quantidade campis dos IFs por região segundo dados de Davidis (2018), com um comparativo da origem da instituição formadora dos egressos estudados das 20 Teses e Dissertações as quais os trabalhos se desenvolveram analisando egressos oriundos de IFs. A partir deste comparativo é possível notar que nas duas regiões Nordeste (206 IFs) e Sudeste (143 IFs) onde está concentrado o maior número de campis de IFs é onde também se concentra a maior quantidade de produções científicas, 9 e 6 respectivamente.

Gráfico 1: Comparativo entre a quantidade de campis dos IFs por região e origem da instituição formadora das Teses e Dissertações selecionadas

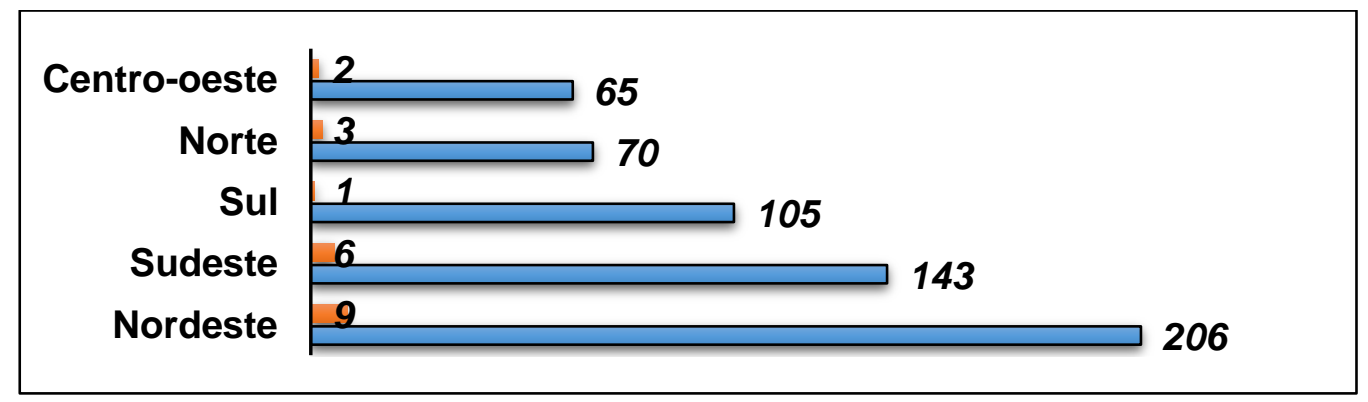

Fonte: Adaptado de Davidis (2018, p. 40)

Ao relacionar o número de IFs e quantidade de lócus de pesquisas investigados nas publicações selecionadas por região, deve-se levar em consideração a política pública que atuou na distribuição regional destes IFs. Tendo em vista a desigualdade populacional e socioeconômica entre as regiões brasileiras.

Diante disso a política de expansão da Rede Federal foi significativa no contexto da distribuição regional de IFs, pois apresentava em seus preceitos 0 
desenvolvimento e as interações regionais como pontos essenciais, os quais foram utilizados na implementação destes novos campis "possibilitaram a sua difusão em regiões periféricas e em mesorregiões que podem ter a sua dinâmica socioeconômica positivamente impactada" (PEREIRA; CRUZ, 2019, p.1).

Desta forma, é notável que a concentração de lócus de pesquisas na região Nordeste nos trabalhos analisados, convergem com o um contexto de busca por desenvolvimento regional.

Ao investigar a qual EEEPs pertencem os egressos estudados, também se destacou a região Nordeste, sendo 4 trabalhos com o lócus de pesquisa no estado do Ceará, o qual no ano de 2018 encontravam-se 119 EEEPs, ofertando 52 cursos, com 15. 181 alunos formados até o ano de 2017, segundo o site da Secretaria de Educação do Governo do Estado do Ceará.

Tendo em vista que as regiões Nordeste e Sudeste se destacaram ao ser verificado os lócus das pesquisas. Cabe mencionar que nem todos os estados pertencentes a estas regiões possuíam instituições que serviram como lócus de pesquisas dentre as produções selecionadas.

Na região Nordeste os estados Ceará e Bahia apresentaram o maior número de instituição pesquisadas 5 e 4 respectivamente, nos estados Maranhão, Piauí e Sergipe foram identificadas apenas uma instituição de cada estado. Além disso, não foram localizadas produções que investigaram instituições pertencentes aos estados do: Rio Grande do Norte, Paraíba e Alagoas.

Na região Sudeste o cenário se diferenciou, pois em todos os seus estados foram verificadas instituições que serviram com lócus de pesquisa, São Paulo, Rio de Janeiro e Espírito Santo com apenas 1 instituição pesquisada em cada um dos estados e Minas Gerais com 3 instituições.

Nas regiões Centro-Oeste, Norte e Sul, em que a quantidade de instituições pesquisadas se apresentou em menor quantidade, não foram verificados lócus de pesquisas pertencentes aos seguintes estados: Goiás, Mato Grosso, Mato Grosso do Sul (região Centro-Oeste), Acre, Amapá, Amazonas, Pará, Tocantins (região Norte) e Santa Catarina (região Sul).

Além das origens institucionais dos egressos, outra análise foi realizada, acerca da fundamentação teórica das produções científicas selecionadas. Com o intuito de conhecer quais foram os principais teóricos estrangeiros e comentadores brasileiros que serviram de fundamentação teórica sobre a EPTNM, levando em consideração a perspectiva do egresso. Inicialmente, foi realizada uma análise dos resumos das Teses e Dissertações na busca pelos nomes dos teóricos e autores. Dentre os 25 resumos examinados, apenas 8 mencionavam os principais teóricos e autores utilizadas em sua produção.

Dentre os autores mais mencionados, 5 são citados nas 8 produções científicas, os autores são: Ciavatta, Ramos, Frigotto e Saviani quatro vezes cada e Antunes, duas vezes. Já a frequência em que os teóricos estrangeiros foram encontrados foi menor, apenas uma vez cada, sendo eles: Marx, Meszáros, Gramsci e Bourdieu.

Como base teórica que abrangesse a temática da formação integrada, ensino médio, educação profissional, os estudos de Frigotto, Ramos e Ciavatta subsidiaram os trabalhos de Grangeiro (2016) discutindo-se o fortalecimento da lógica do mercado 
e o modelo dualista. No trabalho de Marques (2016) abordando o esclarecimento sobre a formação humana integral pretendida na educação profissional e a organização do trabalho com o viés oposto à perspectiva de formação humana. $\mathrm{Na}$ produção de Cardoso (2018) estes autores embasaram a discussão acerca de educação politécnica e omnilateral e em Leal Neto (2018) quando se encontra reflexões acerca do discurso educacional, o paradigma das competências e ensino médio integrado.

Segundo a análise de Leal Neto, ao mencionar a relevância dos estudos de Ciavatta, Frigotto e Ramos, destacando ainda a presença de mais um autor, Moura:

Não há que negar a defesa do ensino médio integrado por parte de um conjunto de educadores marxistas, entre eles Gaudêncio Frigotto, Dante Moura, Maria Ciavatta e Marise Ramos. Para esses educadores, a integração entre educação profissional e ensino médio consiste na "travessia" para outra forma de socialização, ao mesmo tempo em que cria a oportunidade para milhões de jovens brasileiros a terem o direito a um ensino médio pleno e uma formação profissional de qualidade (LEAL NETO, 2018, p. 90, grifos nossos).

As produções de Antunes envolvem o estudo acerca da sociologia do trabalho, as classes trabalhadoras, a teoria social, dentre outras temáticas. $\mathrm{O}$ autor serviu de embasamento teórico para Marques (2016) em que o enfoque da discussão se baseou em debater a acumulação do capital relacionando esta acumulação com os impactos na vida do trabalhador, também foi argumentado acerca da exploração e os desafios no mundo do trabalho. E na produção de Cardoso (2018) ao ser discutido em seu trabalho o desemprego estrutural dentro do sistema capitalista.

Saviani por sua vez desenvolve trabalhos acerca da história da educação brasileira, pedagogia e teorias da educação destacando-se a "Pedagogia HistóricoCrítica". Seus estudos embasaram a produção de Marques (2016) apresentando rompimento entre trabalho manual e trabalho intelectual dentro do contexto histórico, em Leal Neto (2018) relatando os fundamentos ontológicos e históricos da relação trabalho e educação e em Cardoso (2018) destacando a formação politécnica nos termos de Gramsci.

Assim sendo, o conjunto formado pelos estudos destes autores envolvem conceitos essenciais ao entendimento e aprofundamento acerca da Educação Profissional e Tecnológica, o trabalho e o Ensino Médio integrado.

Utilizando, portanto, como base para a investigação estes teóricos e autores, foram analisadas todas as referências das 25 Teses e Dissertações, na busca de conhecer em quantas produções cada teórico e autor foi mencionado e ainda revelar o comparativo entre a utilização de teóricos estrangeiros e comentadores brasileiros nos trabalhos analisados. No Gráfico 2, pode-se observar estas informações. 
Gráfico 2: Quantidade de vezes em que os teóricos e comentadores brasileiros se encontram presentes nas referências das Teses e Dissertações selecionadas

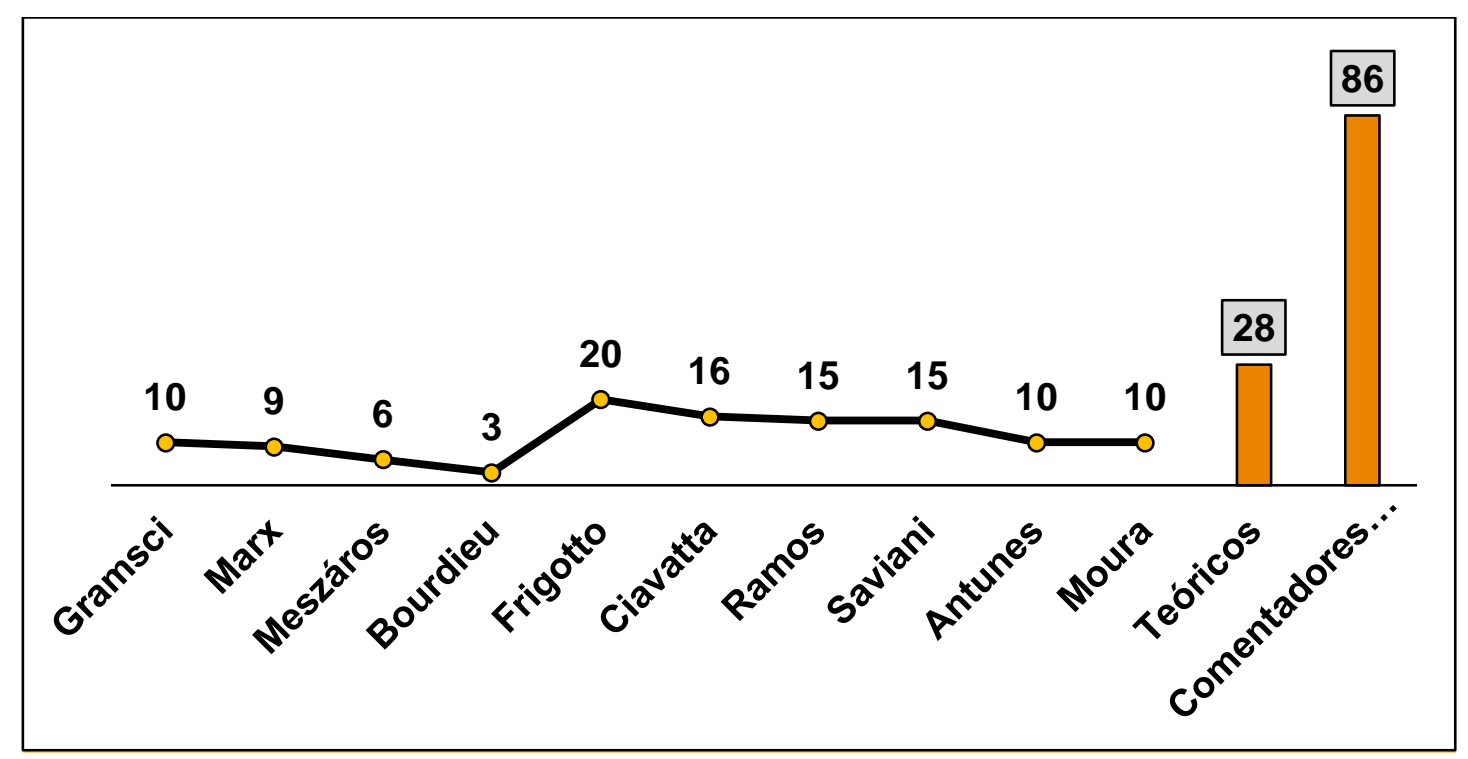

Fonte: Elaborado pelas pesquisadoras a partir dos dados analisados da BDTD (2020)

A análise em relação aos comentadores brasileiros se apresentou mais acentuada em comparação a presença dos teóricos. Como pode ser notado no Gráfico 2, os teóricos foram utilizados em uma frequência de 28 vezes, enquanto os comentadores brasileiros apresentaram uma frequência de 86 vezes.

Dentre os quatro teóricos buscados nas referências (Marx, Gramsci, Meszáros e Bourdieu), Gramsci foi o mais presente, sendo citado em 10 produções, seguido de Marx referenciado em 9 produções. Já no que diz respeito aos comentadores brasileiros buscados nas referências (Frigotto, Ciavatta, Ramos, Saviani, Antunes e Moura), Frigotto esteve presente em 20 produções, ou seja, $80 \%$ dos trabalhos analisados. É possível então concluir que, atualmente, nessa temática os pesquisadores utilizam mais os comentadores brasileiros para fundamentar suas discussões do que teóricos.

Este fato pode ser entendido partindo da hipótese de que a leitura e compreensão acerca dos estudos produzidos pelos teóricos estrangeiros se torna mais difícil em comparação com estudos produzidos nacionalmente. Quando considerada esta hipótese dois pontos principais podem sustentá-la, que são: estudos escritos em outro idioma e traduzidos para o português sofrem algumas alterações que podem dificultar a compreensão e outro ponto parte do fato de que estes estudos foram produzidos em outro contexto histórico, Marx e Gramsci século XIX, Mészaros e Bourdieu século XX, o que requer dos pesquisadores mais atenção e esforço para que os textos sejam compreendidos.

Assim como a fundamentação teórica, a metodologia é outra etapa relevante de conhecimento que se busca apreender quando se analisa produções científicas, tendo em vista a investigação dos instrumentos de coleta de dados mais utilizados em pesquisas nesta temática. Os instrumentos de coleta de dados mais utilizados foram: questionário, entrevista, análise documental, formulário e observação (15, 11, 9, 2, 2 vezes, respectivamente). Cabe relatar que muitos dos autores utilizaram mais de um 
dos instrumentos mencionados, a exemplo do autor Artiaga (2015) que não utilizou dentre os instrumentos encontrados somente o formulário.

A análise documental foi utilizada em 9 dos trabalhos analisados, porém sempre acompanhada de outro instrumento de coleta de dados. Esta técnica, foi utilizada para acrescentar dados aos demais já recolhidos através de outros métodos de coleta. Fazendo ainda uma relação com a análise de dados textuais realizada neste artigo para a formação de uma nuvem de palavras, a qual foram analisados os resumos dos trabalhos, foi possível constatar que a palavra "documental" aparece 12 vezes, o que também revela a frequência em que este tipo de análise é utilizado em produções dentro da temática dos egressos da EPTMN.

A aplicação de questionários se destacou, somando um total 15 trabalhos que utilizaram este instrumento. Diferente das entrevistas em que é necessário ocorrer o contato presencial com o respondente, o questionário se sobressai em pesquisas que envolvem um grande número de sujeitos estudados, por apresentar mais rapidez na coleta de dados e análise. Tendo em vista a maior quantidade de respondentes em produções que envolve análise de egressos a fim de compreender de fato sua realidade, o questionário melhor se aplica nestes trabalhos. Cabe, além disso, mencionar o número de vezes em que as palavras "entrevista" e "questionário" estavam presentes na análise de dados textuais utilizando o software Iramuteq, apresentando-se 17 e 16 vezes respectivamente.

Outro instrumento de coleta de dados utilizado nas produções científicas foram os formulários os quais, bem como as entrevistas, a coleta se dá através do contato direto com o respondente, ocorrendo, portanto, uma relação face a face entre respondente e pesquisador, porém o que diferencia estes dois instrumentos de coleta de dados, é que, o formulário se caracteriza por apresentar menos liberdade por parte do pesquisador no ato da obtenção das respostas, pois se deve seguir de maneira mais rígida o roteiro de questões previamente elaboradas (MARCONI; LAKATOS, 2003, p. 195-212).

A última investigação proposta foi a de análise de dados textuais, desenvolvida com intuito de verificar a frequência em que os dados textuais se apresentaram nos resumos, formando uma nuvem de palavras e seus graus de conectividade, denominada de análise de similitude.

A nuvem de palavras revela as principais palavras que se destacam de acordo com a frequência em que aparecem nos resumos das Teses e Dissertações. As palavras que estão com o tamanho maior são aquelas em que a repetição se tornou mais acentuada, se destacando os termos; "curso técnico", "educação profissional" e a palavra "egresso". Como pode ser observado na Figura 3. 
Figura 3: Nuvem de palavras, formulada a partir do software Iramuteq com os resumos das teses e dissertações analisadas

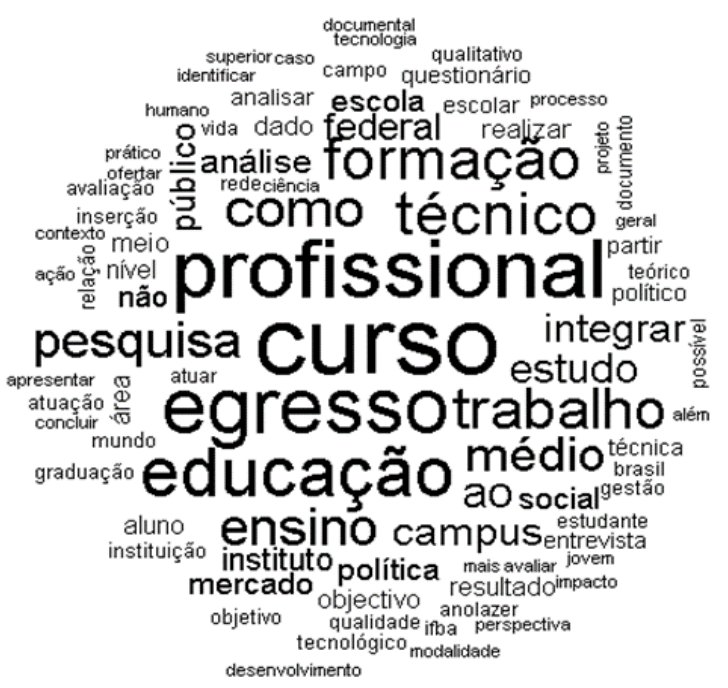

Fonte: Elaborada pelas pesquisadoras a partir dos dados analisados da BDTD (2020)

O conjunto dos termos, encontrados na nuvem de palavras, refletem a temática central destes trabalhos, que é a investigação dos egressos da Educação Profissional, considerando os cursos técnicos ofertados.

A formação de profissionais qualificados para a inserção no mercado de trabalho faz parte dos objetivos propostos através da implementação da EPT. Partindo deste pressuposto a análise da inserção do egresso da Educação Profissional no mercado de trabalho é ponto relevante em muitas pesquisas que abordam esta temática, podendo também ser notável na nuvem de palavras o termo "mercado" com uma frequência de 26 vezes.

Historicamente o mundo do trabalho vem sofrendo transformações abrangendo sua reestruturação produtiva ao longo dos anos e as modificações sofridas economicamente. $\mathrm{O}$ homem na busca de se inserir neste mundo se submete também a mudanças. Antunes $(2007$, p. 17) relata que:

A crise experimentada pelo capital, bem como suas respostas, das quais 0 neoliberalismo e a reestruturação produtiva da era da acumulação flexível são expressão, têm acarretado, entre tantas consequências, profundas mutações no interior do mundo do trabalho.

Se insere neste contexto as compreensões de classe trabalhadora na sua conformação atual. Antunes e Alves (2004, p. 342) relatam as mutações no mundo trabalho, caracterizadas pela heterogeneidade, fragmentação e complexificação, da classe trabalhadora, sendo relevante acrescentar que: 
compreende a totalidade dos assalariados, homens e mulheres que vivem da venda da sua força de trabalho, não se restringindo aos trabalhadores manuais diretos, incorporando também a totalidade do trabalho social, a totalidade do trabalho coletivo que vende sua força de trabalho como mercadoria em troca de salário.

Constitui-se assim, os novos tipos de trabalhadores, que buscam suprir suas necessidades econômicas, se inserindo de forma alienada e precária, no mundo do trabalho.

Para compreender o grau de proximidade entre as palavras mencionadas, fezse a análise de similitude. Esta segundo Camargo e Justo (2013, p.516) "se baseia na teoria dos grafos, possibilita identificar as concorrências entre as palavras e seu resultado traz indicações da conectividade entre as palavras". Pode-se notar na Figura 4 o destaque de 3 comunidades de palavras.

Figura 4: Análise de similitude, formulada a partir do software Iramuteq com os resumos das teses e dissertações analisadas

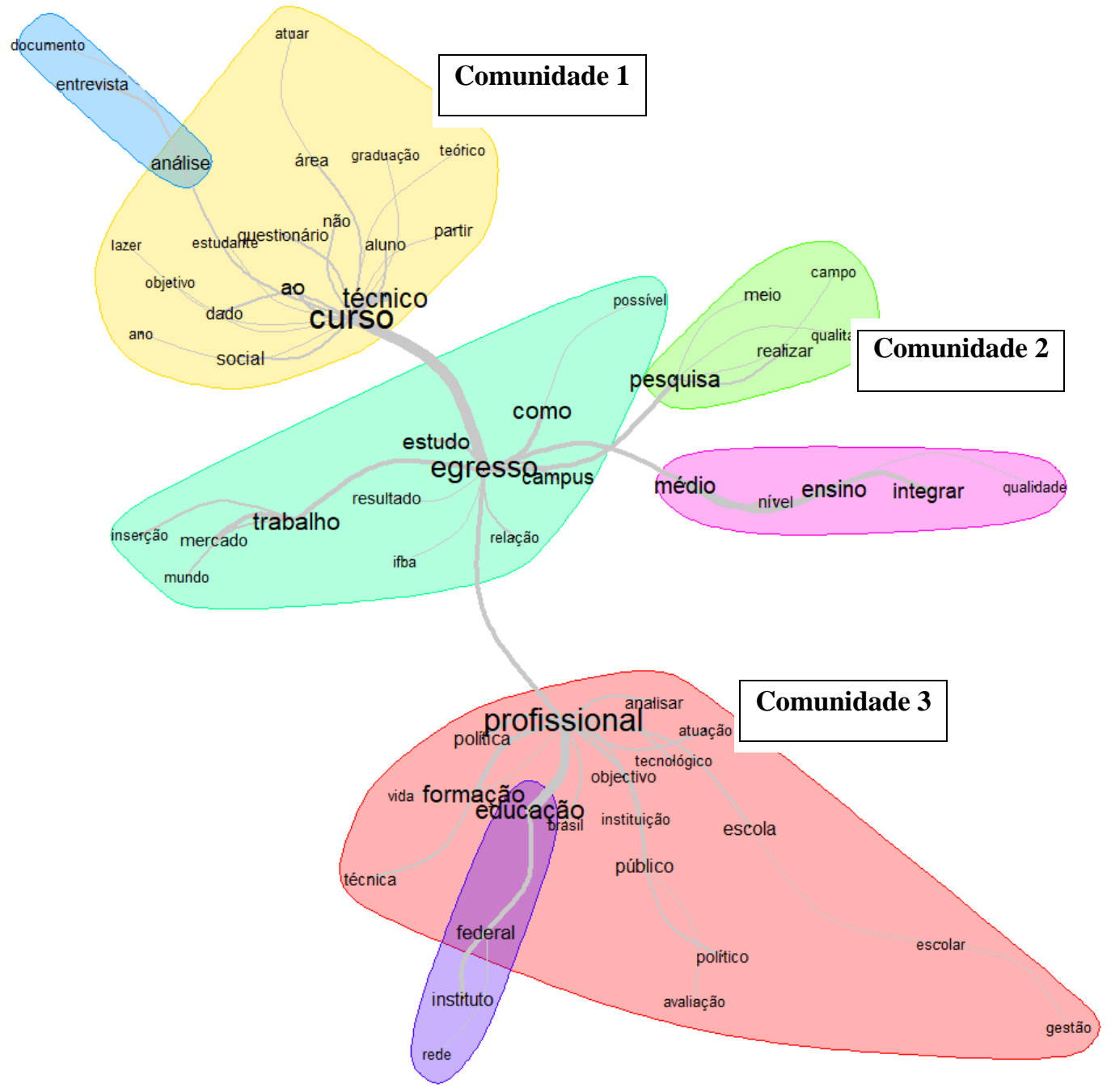

Fonte: Elaborada pelas pesquisadoras a partir dos dados analisados da BDTD (2020) 
Pode-se considerar na comunidade 2 que nas produções científicas analisadas o egresso (85 vezes), é o sujeito das pesquisas. Apresentando uma ligação com a comunidade 3 a qual através da conectividade entre as palavras, é possível verificar os seguintes termos: Educação Profissional (76 e 93 vezes), formação técnica (64 e 17 vezes) e Instituto Federal (29 e 25 vezes), caracterizando desta forma a origem destes egressos.

Outro ponto relevante desta investigação ocorreu através da interpretação por meio de afinidade entre as palavras presentes nas comunidades 2 e 1 , se destacando alguns procedimentos metodológicos, que são: pesquisa qualitativa (53 e 12 vezes) e pesquisa de campo (53 e 15 vezes), verificando desta forma as técnicas de pesquisa mais utilizadas nas produções analisadas. E em relação aos instrumentos de coleta de dados das pesquisas se destacam: análise documental (31 e 12 vezes), entrevista (17 vezes) e questionário (16 vezes).

Além disso, a comunidade 1 apresenta um galho de ligação forte com a comunidade 2, reforçando a modalidade da EPTNM investigada neste artigo, como sendo os cursos técnicos (110 e 65 vezes) do Ensino Médio Integrado (55, 50 e 39 vezes).

\section{CONSIDERAÇÕES FINAIS}

O acompanhamento do egresso da Educação Profissional é imprescindível partindo do pressuposto que através dele é possível revelar as aspirações acerca da formação técnica de nível médio na vida do egresso, podendo apontar, acerca da avaliação da oferta desta modalidade educacional considerando as particularidades dos lócus pesquisados. Assim, as produções científicas neste estudo investigadas, abordam esta temática buscando compreender variadas questões, como a realidade e aspirações dos egressos em relação a inserção no mundo do trabalho, continuação de seus estudos, assim como a implementação da política pública desta modalidade na realidade educacional do país.

Conclui-se que, a partir do número de trabalhos selecionados foi possível notar que existe uma quantidade considerável de pesquisas que permeiam esta temática, 25 estudos com destaque para o ano de 2016 em que foram selecionados 7 trabalhos publicados, os quais podem ser mais frequentes neste período devido a estes terem sido produzidos provavelmente levando em consideração o contexto histórico de expansão da Rede Federal de Educação Profissional e Tecnológica.

Baseado nos dados obtidos através da análise dos lócus das pesquisas, os IFs, foram verificados em 20 produções distribuídas em todas as regiões do país, se destacando as regiões Nordeste (9 produções) e Sudeste (6 produções). Sendo Nordeste e Sudeste os principais lócus de pesquisas das produções analisadas, devido a sua distribuição de campis nas regiões brasileiras se evidenciando consequentemente aquelas mais populosas e com o maior número de campis, as regiões Sudeste e Nordeste respectivamente.

Foi possível constatar que em todos os estados da região Sudeste foram localizados lócus de pesquisas, porém na região Nordeste o cenário se apresentou 
diferente, pois nos estados do Rio Grande do Norte, Paraíba e Alagoas, não houve a ocorrência de nenhuma instituição pesquisada.

Além disso na região Nordeste, os lócus das pesquisas se concentraram de forma mais acentuada em dois estados Ceará e Bahia, representando $36 \%$ de todas as produções selecionadas. Estes dados revelam a carência desta temática ser abordada nos demais estados desta região, com o objetivo de favorecer a descentralização destes lócus de pesquisas. Assim como nos estados das regiões Centro-Oeste, Norte e Sul, tendo em vista a presença menor de instituições pesquisadas nestas regiões, somando um total de apenas 6 produções, 24\% das produções selecionadas.

É notória também a necessidade de produções científicas que analisem os trabalhos encontrados na BDTD que envolvem a temática dos egressos de outras modalidades de ensino, descritas neste artigo: PRONATEC, PROEJA, Subsequente, Concomitante e o Ensino Superior.

Outra análise se desenvolveu acerca dos instrumentos de coletas de dados empregados nas metodologias utilizadas nas produções científicas, as quais revelaram que o número de trabalhos que aplicaram questionários (15 trabalhos) é maior do que a utilização de outro instrumento, devido à facilidade na coleta de dados e análise.

Quando abordado acerca das referências utilizadas para as discussões dentro desta temática, foi exposto que os autores brasileiros são mais utilizados que teóricos estrangeiros, se destacando Frigotto presente em $80 \%$ das produções analisadas. Esta maior frequência de utilização dos autores brasileiros se dá devido a maior facilidade de compreensão dos textos em comparação a textos produzidos por teóricos estrangeiros, tornando dessa forma os autores Frigotto, Ciavatta, Ramos, Antunes, Moura e Dante as principais referências quando se investiga os egressos da Educação Profissional Técnica de Nível Médio.

Por fim, as análises de dados textuais comprovaram a presença da temática do egresso na EPTNM, através da frequência de palavras nos resumos, bem como suas conexões por meio da análise de similitude, desenvolvidas mediante a utilização do software Iramuteq. Que apresentou em seus ramos de ligações entre palavras, o egresso como sendo objeto de investigação, avaliação e estudo dentro da EPTNM, as metodologias que apareceram com maior frequência nos resumos foram os questionários (17 vezes) e as entrevistas (16 vezes). E a presença da modalidade de Ensino Médio Integrado investigado neste artigo.

Assim sendo as produções investigadas e análises realizadas através do mapeamento sistemático produzido, foram capazes de construir um conjunto de informações essenciais que poderão servir de subsídio para a futuros pesquisadores a respeito deste assunto, pois aborda acerca das principais indagações na construção de um trabalho científico, como: onde está localizada a maior concentração de lócus de pesquisa que envolvem este tema, afim de compreender em que região ou estado existe uma carência de pesquisas nesta temática, bem como, saber quais as metodologias mais empregadas e quais atores são mais utilizados para embasar as discussões acerca deste assunto. 


\section{REFERÊNCIAS}

ANDRÉ, Marli, GATTI Bernardete A. Métodos Qualitativos de Pesquisa em Educação no Brasil: origens e evolução. Simpósio Brasileiro- Alemão de Pesquisa Qualitativa e Interpretação de dados. 26 a 28 de março, Brasília, 2008.

ANTUNES, Ricardo; ALVES, Giovanni. As mutações no mundo do trabalho na era da mundialização do capital. Educ. Soc., Campinas, vol. 25, n. 87, 2004, p. 335-351.

ANTUNES, Ricardo. Os sentidos do trabalho: ensaio sobre a afirmação e a negação do trabalho. 3. ed. São Paulo: Boitempo, 2007.

BARDIN, L. Análise de conteúdo. Lisboa: Edições 70, 2006.

BRASIL. Decreto no 6.302, de 12 de dezembro de 2007. Institui o Programa Brasil Profissionalizado. Disponível em: http://www.planalto.gov.br/ccivil_03/_Ato20072010/2007/Decreto/D6302.htm. Acesso em: 10 jan. 2020.

BRASIL. Ministério de Educação e Cultura. LDB - Lei no 9394/96, de 20 de dezembro de 1996. Estabelece as diretrizes e bases da Educação Nacional. Brasília. Disponível em:

https://www2.senado.leg.br/bdsf/bitstream/handle/id/70320/65.pdf. Acesso em: 23 dez. 2019.

CAMARGO, Brigido Vizeu; JUSTO, Ana Maria. IRAMUTEQ: Um software gratuito para análise de dados textuais. Temas em Psicologia, v. 21, n. 2, 2013, p. 513-518.

CORDEIRO, Alexander Magno et al. Revisão sistemática: uma revisão narrativa.

Revista do Colégio Brasileiro de Cirurgiões, 2007, p. 428-431.

COSTA, Angelo Brandelli; ZOLTOWSKI, Ana Paula Couto. Como escrever um artigo de revisão sistemática. In: KOLLER, H. Silva; COUTO, Maria Clara P. de Paula; HOHENDORFF, Jean Von. Manual de Produção Científica. Porto Alegre. Penso, 2014. p. 55-70.

GIL, Antônio Carlos. Como elaborar projetos de pesquisa. 4. ed. São Paulo: Atlas, 2002.

LAKATOS, Eva Maria; MARCONI, Marina de Andrade. Fundamentos de metodologia científica. 5. ed. São Paulo: Atlas, 2003.

LOPES, Ana Lúcia Mendes; FRACOLLI, Lislaine Aparecida. Revisão sistemática de literatura e metassíntese qualitativa: Considerações sobre sua aplicação na pesquisa em enfermagem. Texto \& Contexto Enfermagem, Florianópolis, 2008, p. 771-778.

PERREIRA, L. A. C; CRUZ, J. L. V. Os institutos federais e o desenvolvimento regional: interface possível. Holos, Ano 35, v.4, 2019. Disponível em:

http://www2.ifrn.edu.br/ojs/index.php/HOLOS/article/view/7992. Acesso em: 19 maio 2020.

SILVA, Aleson Belo da et al. Avaliação do plano de expansão da Rede Federal de ensino segundo indicadores de desempenho. XIX Colóquio Internacional de Gestão Universitária. Florianópolis, 2019. Disponível em: https://repositorio.ufsc.br/handle/123456789/201681. Acesso em: 19 maio 2020. 
Revista Brasileira da Educação Profissional e Tecnológica, v. 1, n. 20, e10021, 2021, p. 19 de 19 CC BY 4.0 | ISSN 2447-1801 | DOI: https://doi.org/10.15628/rbept.2021.10021

TURMENA, Leandro; AZEVEDO Mário Luiz Neves de Azevedo. A expansão da Rede Federal de Educação Profissional, Científica e Tecnológica: os Institutos Federais em questão. Rev. Diálogo Educ., Curitiba, v. 17, n. 54, jul./set. 2017, p. 1067-1084. 